
PNQM04

\title{
OTIMIZAÇÃO DE MÉTODO ANALÍTICO POR ESPECTROFOTOMETRIA PARA DOSEAMENTO DE TANINOS TOTAIS NAS CASCAS DE Hymenaea courbaril L.
}

\author{
C. J. L. TENÓRIO ${ }^{1}$, S. L. SILVA ${ }^{2}$, M. R. A. FERREIRA ${ }^{1,2}$, L. A. L. SOARES ${ }^{1,2}$ \\ ${ }^{1}$ Universidade Federal de Pernambuco, Laboratório de Farmacognosia, Departamento de \\ Ciências Farmacêuticas. \\ ${ }^{2}$ Programa de Pós-graduação em Inovação Terapêutica, Centro de Biociências, Universidade \\ Federal de Pernambuco.
}

E-mail para contato: camyllajlt10@gmail.com

RESUMO - Hymenaea courbaril L. é uma espécie da família Fabaceae. Assim como outras do mesmo gênero a $\underline{H}$. courbaril é conhecida vulgarmente como Jatobá. Suas cascas são utilizadas popularmente para tratar diferentes doenças agudas e crônicas como processos inflamatórios, problemas respiratórios entre outras. Neste sentido, o desenvolvimento de métodos analíticos que obedeçam às exigências dos órgãos regulatórios, representa um passo fundamental para caracterização e padronização da droga vegetal. O presente trabalho teve como objetivo otimizar um método para quantificação de taninos totais (TT) nas cascas de $\underline{H}$. courbaril. As condições estabelecidas na otimização de método para doseamento de TT que apresentaram melhores respostas analíticas foram as conduzidas com 0,5 g de droga, sendo em 15 minutos o melhor tempo de reação. Através do planejamento fatorial foi observado que a utilização de $0,25 \mathrm{~mL}$ de folin-ciocalteu e de $\mathrm{Na}_{2} \mathrm{CO}_{3}$ a 15,5\% foram os que apresentaram melhor resposta para o método. Quanto ao agente complexante, a utilização de 150mg de PVP apresentou maior teor da fração não tanante. Após otimização do método, a análise quantitativa resultou em teor de TT de 4,54 g \% calculado como pirogalol. As condições estabelecidas sugerem que o método para o doseamento de taninos totais em cascas de $\underline{H}$. courbaril pode ser utilizado, porém, é necessária a validação do método proposto, a fim de assegurar a confiabilidade do mesmo.

Palavras-Chaves: Jatobá. Otimização. Doseamento. Taninos totais.

ABSTRACT - Hymenaea courbaril L. is a species of the Fabaceae family. Like others of the same genus H. courbaril is commonly known as Jatobá. Its barks are popularly used to treat different acute and chronic diseases such as inflammatory processes, respiratory problems among others. In this sense, the development of analytical methods that obey the requirements of regulatory agencies, represents a fundamental step for the characterization and standardization of the vegetal drug. The present work had as objective to optimize a method for quantification of total tannins (TT) in the barks of $\underline{H}$. courbaril. The conditions established in 
the optimization of method for assay of TT that presented better analytical responses were those carried out with $0.5 \mathrm{~g}$ of drug, and in 15 minutes the best reaction time. Through the factorial planning it was observed that the use of $0.25 \mathrm{~mL}$ folin-ciocalteu and $\mathrm{Na}_{2} \mathrm{CO}_{3} 15.5 \%$ were the ones that presented the best response to the method. Regarding the complexing agent, the use of $150 \mathrm{mg}$ of PVP showed higher content of the non-tanante fraction. After optimization of the method, the TT content of $4.54 \mathrm{~g} \%$ calculated as pyrogallol was obtained. The established conditions suggest that the method for the determination of total tannins in $\underline{H}$. courbaril barks can be used, however, it is necessary to validate the proposed method in order to ensure its reliability.

Keywords: Jatobá. Optimization. Dosing. Total tannins.

\section{INTRODUÇÃO}

Hymenaea courbaril (Fabaceae) é uma espécie conhecida popularmente como jatobá, jitaí, jataí, não endêmica, porém com ocorrências registradas em todas as regiões do Brasil (LORENZI, 1992). Evidências experimentais confirmaram que espécies do gênero Hymenaea são utilizadas no tratamento de distúrbios inflamatórios, asma, diarreia e algumas infecções microbianas (BONIFACE, FERREIRA, KAISER, 2017). O uso popular de $H$. courbaril e as comprovações farmacológicas na literatura despertam o interesse para aprofundar o conhecimento acerca da identificação e quantificação dos metabólitos da espécie, a fim de padronizar extratos obtidos da droga vegetal.

Dessa forma, a padronização de soluções extrativas é uma etapa fundamental para assegurar a qualidade e reprodutibilidade de preparações vegetais. Portanto, a identificação e quantificação dos efeitos de fatores que, possam atuar sobre a qualidade dos parâmetros de extração, permitem promover ajustes operacionais capazes de maximizar a qualidade e minimizar a variabilidade do processo. Nesse contexto, inseremse os planejamentos fatoriais que produzem dados capazes de detectar e estudar o efeito destes fatores, utilizando modelos estatísticos e assegurando a obtenção de resultados com menor quantidade de erros aleatórios (CUNHA et al., 2009; LIMA et al., 2015).

\section{MATERIAIS E MÉTODOS}

O material vegetal constituído das cascas foi coletado em Buíque (PE) e identificado no Instituto Agronômico de Pernambuco sob no ${ }^{\circ}$ 91547. Em seguida, o material foi seco em estufa durante 7 dias à temperatura de $40-45^{\circ} \mathrm{C}$. Após secagem as cascas foram trituradas em forrageira.

A droga vegetal foi submetida a extração por refluxo utilizando $1 \mathrm{~g}$ da droga vegetal e adicionados $150 \mathrm{~mL}$ de água destilada em balão de fundo redondo com capacidade para $250 \mathrm{~mL}$. A preparação foi mantida sob refluxo durante 30 minutos à temperatura de $85^{\circ} \mathrm{C}$ e, em seguida, resfriada até a temperatura ambiente. O conteúdo foi transferido para balão volumétrico de $250 \mathrm{~mL}$ e o volume completado com água destilada. A solução foi deixada em repouso para decantar e filtrada em papel de filtro, desprezando os primeiros $50 \mathrm{~mL}$, e o filtrado restante constituiu a Solução Estoque (SE). Uma alíquota de $5 \mathrm{~mL}$ da $\mathrm{SE}$ foi transferida para balão volumétrico de $25 \mathrm{~mL}$, constituindo a solução amostra (SA).

Por fim, foram avaliadas as condições analíticas a seguir: determinação da concentração da amostra; comprimento de onda de leitura da amostra, após varredura realizada entre 500 a $900 \mathrm{~nm}$ em espectrofotômetro; cinética de reação (0-60 min); 
proporção droga: solvente $(0,5$ - 1,5 g); avaliação da quantidade do reagente FolinCiocalteau e concentração de $\mathrm{Na}_{2} \mathrm{CO}_{3}$ através de planejamento fatorial; e, avaliação da quantidade de agente precipitante polivinilpirrolidona (PVP - 100, 150 e $200 \mathrm{mg}$ ).

O teor de taninos totais foi calculado através da equação abaixo, expresso em $\mathrm{g} \%$ de pirogalol.

$$
T T=\frac{(A 1-A 2) \cdot m 2 \cdot F D}{A 3 \cdot(m 1-p)} \quad(\text { equação } 1)
$$

Onde: $\mathrm{TT}=$ taninos totais $(\mathrm{g} \%)$; $\mathrm{A} 1$ = absorbância de polifenóis totais; $\mathrm{A} 2$ = absorbância da fração nãotanante; A3 = absorbância do pirogalol; FD = fator de diluição; $\mathrm{m} 1$ = massa do padrão pirogalol (g); $\mathrm{m} 2$ = massa da droga vegetal; $\mathrm{p}=$ perda por dessecação da droga vegetal $(\mathrm{g})$.

\section{RESULTADOS E DISCUSSÃO}

Após varredura espectrofotométrica das amostras na faixa de 500 a $900 \mathrm{~nm}$, o máximo de absorbância foi observado em $780 \mathrm{~nm}$ para a amostra de concentração igual $40 \mu \mathrm{L} / \mathrm{mL}$, e com valor de 0,500 U.A. A cinética reacional revelou estabilidade após 15 min de reação. Considerando a proporção droga:solvente, os dados revelaram redução no teor de polifenóis totais $(7,64 \%$ a $6,09 \%)$ quando utilizada quantidade de droga superior a $0,5 \mathrm{~g}(8,34 \% \pm 0,3761)$.

A análise dos dados do planejamento fatorial demonstrou que maior desempenho do método foi alcançado com $0,25 \mathrm{~mL}$ do reagente Folin-Ciocalteau e $\mathrm{Na}_{2} \mathrm{CO}_{3}$ a $15,5 \%$. Ambos fatores analisados apresentaram influência sobre o teor de polifenóis totais $\left(\mathrm{Na}_{2} \mathrm{CO}_{3}:+8,66\right.$ e Folin-Ciocalteau: - 2,65), não sendo evidenciada interação importante entre eles.

Figura 1 - Gráfico de Paretos (A) e Superfície de Resposta (B) obtidos para análise de Folin-Ciocalteau e $\mathrm{Na}_{2} \mathrm{CO}_{3}$ sobre o teor de polifenóis totais.
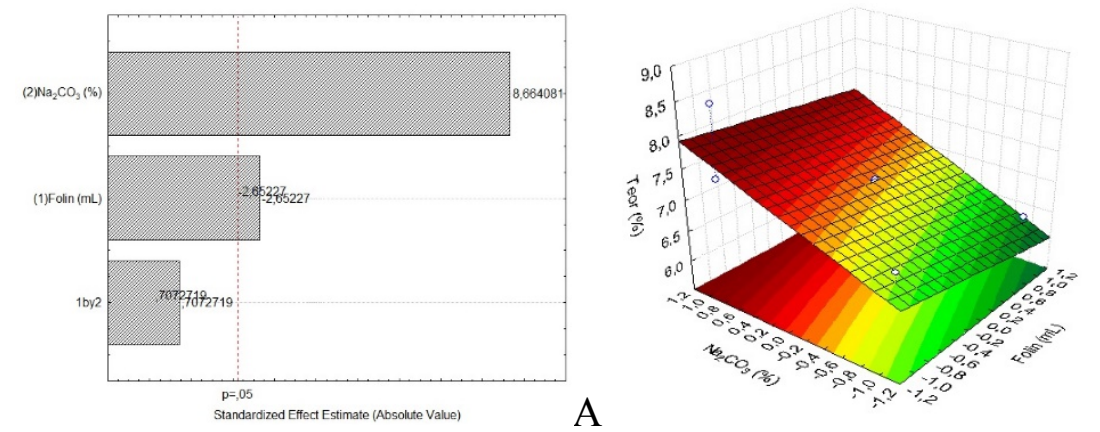

As análises conduzidas com $150 \mathrm{mg}$ de PVP apresentaram maior teor de taninos totais, igual a 4,45 $\pm 0,1467(3,29 \%)$ calculado em $\mathrm{g} \%$ de pirogalol.

\section{CONCLUSÃO}

A otimização do método analítico é um passo fundamental e indispensável para posteriores análises quantitativas de matérias primas vegetais, pois a otimização assegura a escolha dos parâmetros adequados para obtenção das melhores condições para quantificação dos marcadores. Dessa forma, as condições avaliadas, foram estabelecidas de acordo com as melhores respostas analíticas em relação ao teor de polifenóis/taninos totais. Ainda são necessários estudos acerca da validação do método proposto, a fim de assegurar a confiabilidade do mesmo para seu emprego na rotina analítica. 


\section{REFERÊNCIAS}

INOVAÇÃO TERAPEUUTICA

BONIFACE, P. K.; BAPTISTA FERREIRA, S.; ROLAND KAISER, C. Current state of knowledge on the traditional uses, phytochemistry, and pharmacology of the genus Hymenaea. J. Ethnopharmacol., v. 206, n. Supplement C, p. 193-223, 2017.

CUNHA, F. P.; COSTA, L. J. L.; FERNANDES, A. J. D.; SOUZA, T. P.; SOARES, L. A. L. Development and optimization of extractives from Astronium urundeuva (allemão) Engl. by factorial design. Braz. Arch. Biol. Technol., v. 52, p. 647-652, 2009.

DUTRA, R. C. et al. Medicinal plants in Brazil: Pharmacological studies, drug discovery, challenges and perspectives. Pharmacol. Res., v. 112, n. Supplement C, p. 4-29, 2016.

LIMA, B. S.; RAMOS, C. S.; SANTOS, J. A.; RABELO, T. K.; SERAFINI, M. R.; SOUZA, C. S.; SOARES, L.A.L.; QUINTANS-JUNIOR, L. J.; MOREIRA, J. C.; GELAIN, D. P.; ARAUJO, A. A.; SILVA, F. A.. Development of standardized extractive solution from Lippia sidoides by factorial design and their redox active profile. Rev. Bras. Farmacogn., v. 25, p. 301-306, 2015.

LORENZI, H. Árvores brasileiras: manual de identificação e cultivo de plantas arbóreas nativas do Brasil. Nova Odessa: Plantarum, 352 p, 1992.

\section{AGRADECIMENTOS}

Os integrantes agradecem a FACEPE (APQ-0493- 4.03/14) e ao CNPq (308386/20159). 